\title{
THE USE OF EDUCATIONAL PLATFORMS AS TEACHING RESOURCE IN MATHEMATICS
}

\author{
Marcela Gómez-Zermeño ${ }^{1}$ [D, Héctor Franco-Gutiérrez ${ }^{2}$ [D \\ ${ }^{1}$ Tecnológico de Monterrey (Mexico) \\ ${ }^{2}$ Fondo Nacional para el Fomento de las Artesanías (FONART) (México) \\ marcela.gomez@itesm.mx,A01314400@itesm.mx
}

Received October 2017

Accepted February 2018

\section{Abstract}

Dropping out from the school system at High School level has been a problem for several years; high levels of mathematics' failing have been a recurring situation. This paper discusses how academic virtual counseling might be a tool to help students in math class. The methodological approach is based in the non-experimental, longitudinal model evolution and in the designs of evolutionary group analysis, we stated the possibility to generalize the results of the use of technological resources in the teaching of mathematics in order to find out if it is possible to improve the levels of students at a school in upper level education. According to this research, the use of educational platforms as a resource for the subject of mathematics represents not only a technological tool for teachers but also offers students the opportunity to view this subject as an academic challenge to overcome.

Keywords - Mathematics, Educational platform, Student's opinions, Didactic.

\section{Introduction}

Upper secondary education is the level that precedes university studies, with students who are between 14 and 18 years old, age in which adolescents must face complex moments and situations. In this context, increasingly more young people do not finish their studies due to different situations such as family, school, economic problems, and even violence. To drop out means that students withdraw from the courses they are enrolled in, which affects the school's terminal efficiency. It is an indicator that allows to appreciate the behaviour of a generation's school flow.

In México, since the Reform of Higher Secondary Education (RIEMS, Reforma Integral del Nivel Medio Superior) was implemented, dropout problems continue in growth and, therefore, continue to be a priority of educational policies because the dropout rate has not decreased as expected. While the Mexican Secretariat of Public Education (SEP, Secretaría de Educación Pública) recognizes that socio-economic issues are one of the causes of student dropout, there are other causes related to academic factors, which schools should be able to influence and solve.

Technology and innovation within planning designs often show that there is no knowledge about alternatives or options for students' inquiries outside the classroom. The use of the information and communication technology (ICT) which should be essential, according to the profile of the teaching within the RIEMS, is not yet positioned as an educational tool, mostly due to unfamiliarity with teaching strategies using technological resources. 
Every day students use social networks and the internet, elements present in their daily lives, while teachers often do not know students' concerns and different ways to get to the information and knowledge. In this sense, the use of technology is key to integrate different tools that decrease the failing levels in subjects, such as maths, that cause students to dropout. Technology's importance is such that academics talk about the digital gap as one of the marginalization elements between people, countries and groups in the knowledge society (Cabero, 2004).

Recognizing the causes that originate high levels of failing students to reduce these levels requires identifying the strategies teachers use in their practice, as well as the use technology in their teaching and the measurement of its effectiveness. It is considered that a large number of the students who drop out of school do so because of the subject of mathematics. Considering that Mexico's RIEMS suggests the reduction of high school dropout rates, the following question arises: How might virtual academic counseling be a tool for reducing failing rates in high school mathematics? The overall objective of the research was to document strategies that contribute to the reduction of students who fail mathematics and to reduce high school dropout rates. To reach this objective, this research aimed to identify if virtual academic counseling could be a tool to reduce failing indexes in the subject of mathematics of adolescent students.

Within the RIEMS, competencies are defined as the ability to use cognitive resources to face situations with good judgement, to define and solve real problems. Competencies go beyond basic skills or knowhow since they involve the knowledge of how to act and react (Mastache, 2003). Thus, high school programs should promote relevant topics and the construction of knowledge according to the reality, including situations in everyday life contexts.

In this way, RIEMS is a reform with a holistic focus that includes learning to do, learning to know and also attitudes and values (Lozano, 2011); on the other hand, it also notes competencies in performance and is related to the student's responsiveness. Accordingly, the competencies established in RIEMS include behavioral, constructivists and holistic approaches, in other words, is a comprehensive reform.

\section{Innovation in the mathematics teaching field}

According to the High School's mathematics program, its aim is to lead to the development of creativity and logical and critical thinking, through processes of reasoning, argumentation, and structuring of ideas that lead to the development of knowledge, skills, attitudes and values, in the resolution of mathematical problems. The subject of Mathematics aims to allow the student to use different algebraic procedures to represent relationships between constant and variable magnitudes and solve problems of everyday life. Mathematics as a subject should have a relation with the student's surroundings and context, and it must take into account the possible relationships with other disciplines in a transversal approach.

One of the stronger trends in the growth and evolution of mathematics and its teaching is currently given by the power of new technologies (Goldenberg, 2003). Teaching, supported by technological means, offers a lot of possibilities for education: technology can facilitate the learning of concepts and materials, it can help solve problems and contribute to the development of cognitive abilities (Jonassen, Howland, Marra \& Crismond, 2008). While it is true that the use of technologies can benefit students with new and different teaching strategies, it can also provoke new ways of social exclusion and digital gaps among students.

Educational change does not depend on digital technology, but on the teachers' and students' role modification and the relationships between them. In this way, the change from the traditional paradigm should promote emerging practices more aligned with technologies' potential and innovation. Correa and Pablos (2009) reviewed research related to the integration of new technologies in the school system, and found studies about the effects of computers in students' learning performance and knowledge acquisition of a particular subject; they also highlight studies about computers' use at schools in real contexts. Technology incorporation into different courses involves thinking about the content and 
methodology that are taught (Salat, 2013): that is, to go beyond adding some topics related to technology to current plans.

\section{Method}

This research sought to collect empirical evidence on the study's subject and creation of knowledge based on data analysis to scrutinize whether virtual academic counseling could be a tool to reduce failing indexes in the subject of mathematics of adolescent students.

The work was based on the qualitative method, which according to Valenzuela and Flores (2012), brings together different types of research, which share the constructivist and phenomenological paradigms' characteristics, and its focus is understanding and meaning. In addition, the approach a non-experimental, longitudinal model with an evolutionary design analysis about a part of the students' population, taking the specific group of students who had the less successful records in the area of mathematics.

As Merriam (2009) establishes, the central concern is to understand a phenomenon from the participants' perspectives and not from the researchers'; from the students, answers to the exploration questions, will emerge. Therefore, data extracted from the students added meaning to the relevance and effectiveness of the instruments, as well as to the virtual educational tools: it is paramount to have precise instruments to avoid an inaccurate result.

Qualitative researchers are interested in how the people interpret their reality and what meanings they attribute to their experiences (Merriam, 2009); the results emerged from the data obtained through the implementation of the instruments and in addition to the perceptions of the students themselves.

\subsection{Participants and their context}

The sample was obtained from a High school in Nezahualcóyotl, State of Mexico; the students were enrolled in the first-year mathematics class. Students had a history, in their academic record, of failed mathematical studies. The students are natives of Nezahualcóyotl's municipality, considered as a low socio-demographic area with serious problems of crime, being part of the students' reasons to dropout, representing $5 \%$ of the 2013 -B semester.

Three students were selected for the sample, who allowed the researchers to obtain information about the use of technological resources to study, time devoted to strengthening knowledge in virtual counseling and above all, the functionality of building mathematics skills in a virtual environment to obtain better results in the classroom.

The students selected had a poor academic record in the field of mathematics. One of the selected students was studying the subject for the second time and was in danger of dropping out since school regulations state that a student who fails a subject twice is deregistered from the program. The other two students showed difficulties in mathematics from the previous semester.

Thus, as stated by Hernández, Fernández and Baptista (2010) within homogeneous samples of qualitative research, selected units have the same profile or characteristics, in this case, little success in the study of mathematics.

\subsection{Instruments and application procedure}

We designed a tutoring course in the Moodle platform, which is available free of charge, with the purpose of establishing tutorials, virtual interactions, and significant activities for the math class. The topics within the platform were aligned to the math exams, in order to inquire about the use of the platform's effect on academic performance. On the other hand, the mathematics strengthening was related to the classroom course. 
Existing resources from the web were also used: Path to Math, for example, helped the students to strengthen their knowledge of basic math in issues of pre-algebra and elementary algebra, in order to balance their basic knowledge and also to familiarize students with the use of technology platforms to study the math.

Structured interviews with students and their teacher were the instruments to collect relevant data that reflected the way in which students built their knowledge and the value that the virtual tutoring of math had in the perception of the students (Valenzuela \& Flores, 2012).

The process of the investigation was conducted in the following manner:

- Meeting with the Zone Coordinator on the relevance of carrying out the project and obtaining the permission to do it.

- Meeting with 20 students to explain briefly the objectives of the research and the activities to be performed during the process. Some students saw it as additional work to their load, so only three students who showed availability and complied with the requirements for the study were selected.

- Once the sample was chosen, we asked for the approval of their parents, through a talk in which the reasons and objectives of the research were explained to each of them. Each of them agreed without showing signs of disapproval and encouraging their children with the idea of excelling in a complicated subject for them in all their academic history.

- Subsequently, a date was established to conduct the interview.

- Structured interviews with participating students. Given the responses of the students about their own interests, we identified the students' lack of knowledge of the use of educational platforms or any other virtual tool, so we analyzed the first approaches to technological resources for tutoring in the field of mathematics.

- Initial training and using virtual platforms via the existing page's Path to Math.

- Started the tutoring with the Moodle platform and Khan Academy of the school math's topics.

\subsection{Initial interaction with the educational platforms}

At first the use of the platform was difficult for students due to their lack of time management skills; students did not have the disposition to working independently on the educational platforms as there was no direct supervision from the teacher.

Students learned about the technological resources available, Path to math, and their activities; they made a time management commitment to use the platform in a frequent and responsible manner. There was no cost to them to use the platform.

The course created within the Moodle platform reviewed the math topics from the two following exams, and tracked their progress keeping a record on their grades. At this point, the students established a mechanism similar to that carried out within their classes since they were looking to obtain a better grade regardless of the learning processes. That is, the commitment was established directly with having to comply with what had been determined at the time of participating in the project.

The Khan Academy platform was used after Moodle. In it, students found a very different scheme to learn math, since it offers topics that the student can develop. The platform creates different expectations since the tests defined a new level offering characters that create a distinct identity in students, extrinsic motivation is to reach a new level, as in video games. Students liked this platform since it offered them a real desire to interact with it without a prior planning or a purely academic commitment. 


\section{Results}

Interviews were carried out for three days in a week of regular classes; the interviews took place at the school principal's office. Table 1 describes specific characteristics of the participant students:

\begin{tabular}{|c|c|c|c|}
\hline Student & Semester & Status & Subject \\
\hline A & Forth & Repeating student & Mathematics II \\
\hline B & Second & Regular student & Mathematics II \\
\hline C & Second & Regular student & Mathematics II \\
\hline
\end{tabular}

Table 1. Description of the students and their academic status

The participant school defines a repeating student as a student who has failed one or up to three subjects during the semester. Regular students are those who are not repeating any class.

In the implementation of the study, the existing web platforms were used first. The Path to Math platform served as the start to introduce students to current educational technologies and specially to familiarize them with the use of existing and free virtual alternatives on the web. Path to Math develops areas of basic algebra with the idea of regularizing students. This platform is free for up to a month, so it was used the first month to enlist students and observe their progress within the platform. The students were interested above all because they had not seen any platform like it before. The student $\mathrm{C}$ mentioned: "on the platform I can advance to the next level and have a nicer avatar, in fact, I'm using this platform also for fun."

The Math teacher was consulted in order to learn the opportunity areas of the class and the topics where students have greater problems, in order to search the appropriate topics for the next platform. Subsequently students signed up to the Khan Academy platform, in which virtual classrooms were created with the topics suggested by the teacher; students committed to spend at least five hours a week to review the contents and the activities that were included within the platform. The main advantage is that the topics in the platform were developed in such a way that the teacher could enroll students on specific topics of the subject, which included the topics she considered important to strengthen, as well as those that would allow them to continue advancing in the subjects' units.

One of the advantages offered by the Khan Academy platform is to develop the habit of study since it offers different themes which invites students to acquire points and achieve goals. Students liked this since the platform had practice exercises, tutorials, and tests that allow to know the progress of students. On the other hand, teachers can enroll students and observe their progress or their performance in more difficult topics. The main disadvantage was that being a virtual and asynchronous tool, it was difficult to carry out a continuous observation since the main idea was to allow students to discover their own interests within the platform and mostly to use it as a study aid to solve their concerns on the subject.

The motivation for studying math and the importance the students see in it showed the expectations that students have, and especially the way in which they are predisposed to it. On the other hand, we intended to know if the students found the holistic approach to the mathematics stated by the RIEMS, which include learning to do, learning to know and also attitudes and values.

The first point of analysis were the answers that emerged from interviews. Student A mentions that he doesn't like math; students $\mathrm{B}$ and $\mathrm{C}$ mentioned they do like it. However, they do not to understand it because "they need to study more."

Students mentioned not knowing the meaning of competencies, this it is noteworthy because students have worked under the competency-based model from their first semester. However, they do not have clear idea of what that means. Student $\mathrm{C}$ mentions that the development of competencies is important because he can measure his work with that of other students; students A and B could not show any idea on what competencies are. 
Despite not knowing about competencies, students believe that their teacher teaches based on competencies even if they really do not know how the teacher does it. Student $\mathrm{C}$ mentions that the teacher forms teams in class and they compete between them, which reflected, according to the student, the way in which the teacher teaches her classes with competencies. This reflects the lack of clarity that students have about the competencies when entering high school; thus, students demonstrate that they continue to give more importance to the topics and their contents than to the development of their own learning and competencies.

The 3 students stated that to improve their level in the math class they need constant exercises to practice, they also considered the teacher's explanation crucial to understanding the subject. Only student $\mathrm{C}$ refers to various dynamics and the group games as objects that could be motivating for learning the subject. In addition, students mentioned that paying attention is essential in order to understand the subject as well as doing homework through exercises. No doubt the exercises must be an important part in the development of the field of mathematics. However, it is important to produce demonstrable, significant and vital learning and also to encourage students to discovery and the construction of their knowledge and attitudes (Lozano, 2011).

Students considered at the same time that grades are very important to them; student A mentions that they are important for his parents, student B also refers to their importance, although he mentions that he is not concerned, so he does not strive as much as he should. Student $\mathrm{C}$ mentions that grades are of the utmost importance since he considers them to be socially well seen; besides he considered knowing math as an occupational advantage. This topic shows that students value more their grades than their learning, which hinders the teaching-learning process since students tend to use inadequate learning strategies, such as memorization.

On the use of mathematics in everyday life, students considered that they are relevant, especially for operations that are carried out commercially as counting money and basic business operations. Student B also considered the use of mathematics in statistics and the use of the watch. At this point students should already have developed topics of algebra and elements of basic math since junior high school. However, they continue to show lag, and especially that the models of the development of competencies in mathematics remain at the basic level of arithmetic.

Homework, according to the students, is carried out through the notes made in class and verification of exercises also conducted during class hours. Student $\mathrm{C}$ mentions that he needs a comfortable space to do it and be concentrated for the accomplishment of his tasks. When students have questions about the topics in class and are not able not consult with the teacher, they prefer to ask their classmates. In the case of student $\mathrm{A}$, he mentions that he asks family and student $\mathrm{B}$ mentions that he watches tutorials available on YouTube.

Students mentioned consulting tutorials in YouTube videos and find them using search engines. They do not know of any other technological resources available, only student B had previously used a school a platform with math exercises, where he could do activities already planned by the teacher; these activities were interesting to him and formed part of the educational program.

Students unanimously considered that using new and different technological resources can improve their grades. According to student B, they have the possibility to do unlimited practice exercises, and they can review topics in a recurrent way and return to the issues that were not understood. On the other hand, the $\mathrm{C}$ student considers that using the technology can improve their grades since he considers it as a means of entertainment.

Students mentioned that the teacher only suggests internet to do review exercises, as well as tutorials, however, she does not consider the use of technology as part of the graded activities in class. The students' final grades in the semester do not reflect an optimum level of learning, as students A and C 
scored 6.0 and student B 7.0. The student who had repeated the math course and who already had some experience in the use of educational platforms had a higher grade.

From these results and the interviews, we identify the following as elements by which the students have presented recurrent failures in the field of mathematics:

1. Lack of understanding. Which leads to study the academic problems that the student has had since he joined the education system from the basic level.

2. Little attention in the classroom. Attention is fundamental to achieve knowledge; teacher's control of group should allow activities to gain the interest of all students. The teacher should design a learning environment as the articulation of the circumstances and factors that positively affect the learning process (Lozano, 2011)

3. Priority on the grades and not on learning. This means that students are mostly interested in grades; they continue to see their educational development as just passing the courses to advance and not as the development of desirable attitudes.

4. Students do not show acceptable study habits, nor an academic reflection on the subject. The students do not know how to manage their time, the fact that sometimes the students found difficult to work on the platform to perform practice exercises was due to the idea they hay that they were doing it to have a better grade and not as a means of learning.

5. The technological resources use traditional techniques such as a recorded video class. The student usually looks for the traditional approach which they can replay in the video class recorded. Therefore, the students indicated that one of the advantages of the technology was to replay the class and topics as many times as possible. However, this does not respond to the use of technological competencies.

6. There is no motivation for the study of math. Mathematics remains a stigmatized subject that produces a conflict in the student mostly because, as we have pointed out, the student sees the class as an academic requirement to pass a class, and not as a mean to acquire generic competences.

In the case of the teacher, the following elements were found on the interview:

1. Classes do not contain projects or comprehensive products that convey the idea of mathematics as relevant in the syllabus. Rimari Arias (1996) mentions that teacher is only qualified for the transmission of the contents and therefore to teach the class is not enough. Instead, they could use strategies and resources for meaningful learning which are linked to the needs of the students.

2. There is not a clear idea about competency-based teaching, so it is not possible to apply it in class. Andere (2013) mentions that before a competency-based curriculum, it is necessary to have a teacher formed for a competency-based pedagogy, i.e. a pedagogy of learning and not only of teaching.

3. Classes follow the traditional rhythm since the students continue to focus their learning on the teacher. Therefore, students seeks a better explanation than a relevance of the topics. As Alemán and Gomez-Zermeño (2012) point out, the role of the teacher must be of a leader who in turn becomes a facilitator to help students succeed and not to give orders.

4. The classwork does not show relevance on some comprehensive product; rather it is mainly used for the repetition of exercises. Alemán and Gomez-Zermeño (2012) mention that the teacher must have high expectations in students, clear objectives, a disciplined environment, strong supervision and improvement teams. In this way, classwork could move from a requirement or a simple grade to a clear and planned objective. 
5. The teacher shows that she does not know of technological resources to implement in class, and furthermore, she recommends some than follow traditional methods and she does not include them with specific goals in their planning. Educational technology proposals seek to innovate in the teaching-learning process, placing within reach of the student an educational complement to the classroom (Mendoza, Gómez-Zermeño \& Gómez-Zermeño, 2013). Therefore, the teacher has not searched for different resources because she does not know about them.

The development of projects in which students participate can engage them with their studies and thus lower the levels of desertion. In this regard, despite the academics conflicts the students show, all of them still registered for the 2014 school year, despite a subpar performance in their classes. In addition, despite the teacher's results, research invited her to develop new teaching strategies that allow linking technology strategies with the planning of classes. Teachers, in general, gained greater insight on how to use technology to support environments for learning and strengthening school projects' activities.

All students continue using the Khan Academy platform, especially student C, primarily because he found interesting to accomplish the different phases. Students A and B claim that they could use different technological platforms for other subjects. The most important part in the teaching model is undoubtedly the teacher planning, since the specific objectives and hence the relevance of technological resources that can support to reach them emerge from the same.

\section{Conclusions}

The study research question asked whether virtual academic counseling could be a tool to reduce failure rates in the subject of mathematics, to which according to this study indicates that there is a possibility to develop tools and mechanisms within classrooms and outside them that can aim at raising the chances of students to get a better performance in the class and attain a greater learning and strengthening.

The technological tools demonstrate that they can open a range of options for teachers in the subject of mathematics. However, their sole existence does not exempt the teachers' work which is essential. Knowledge of the objectives of the subject and the competency attributes that students will develop during their courses must be assessed by the teacher in order to have clarity in the methods and tools that can be used both inside and outside of school.

On the other hand, the teacher has a possibility of strengthening knowledge in virtual classrooms, which have the advantage of being able to carry out projects aimed at improving the attributes that students reach on the subject. In addition, to that within the teaching, competencies is the use of Information Technology and Communication.

Constant motivation and performance evaluation may favor that students can visualize math class from the perspective of daily life and can also bring the subject to a higher level by transverse projects that promote the relevance of it with mediate and immediate effect. Thus, the subject can go from being a curricular requirement to a specific learning means.

The strategies within the study made use of existing technology platforms, which allowed students to integrate different tools that showed new ways of strengthening their classroom studies of mathematics. In this sense, the students showed that they are open to the possibility of new and different study environments that might encourage the study of mathematics.

The use of virtual platforms can be very helpful if teachers use it from planning their classes and as an ally in the pursuit of the objectives and goals of education, besides enabling greatly to ensure the student attains knowledge that must be constantly reinforced. That is why from the planning of the subject, teachers must specify how they will use technological tools in order to assess the impact thereof and to quantify the gains made by students during the course. 


\section{Declaration of Conflicting Interests}

The authors declared no potential conflicts of interest with respect to the research, authorship, and/or publication of this article.

\section{Funding}

The authors received no financial support for the research, authorship, and/or publication of this article.

\section{References}

Alemán, L., \& Gómez-Zermeño, M.G. (2012). Liderazgo Docente para la Enseñanza de la Innovación. Revista de Investigación Educativa de la Escuela de Graduados en Educación, 2(4), 2-7. Retrieved from: http://rieege.tecvirtual.mx/index.php/rieege/article/view/1

Andere, E. (2013). La escuela rota. Sistema y politica en contra del aprendiraje en México. México: Siglo XXI.

Cabero, J. (2004). Formación del profesorado en TIC. El gran caballo de batalla. Comunicación y Pedagogía. Nuevas tecnologías y recursos didácticos, 195, 27-31.

Correa, J., \& Pablos, J. (2009). Nuevas tecnologías e innovación educativa. Revista de Psicodidáctica, 14(1), 133-145. Retrieved from: http://www.ehu.eus/ojs/index.php/psicodidactica/article/view/255/251

Goldenberg, P. (2003). Pensando sobre tecnología en la clase de matemáticas. Retrieved from: http://www.eduteka.org

Hernández, R., Fernández, C., \& Baptista, P. (2010). Metodología de la investigación. México: McGraw Hill.

Jonassen, D., Howland, J., Marra, R.M., \& Crismond, D. (2008). Meaningful Learning with Technology. Upper Saddle River, USA: Pearson Education.

Lozano, A. (2011). El éxito en la enseñanza. Aspectos didácticos de las facetas del profesor. México: Trillas.

Mastache, A. (2007). Formar personas competentes. Desarrollo de competencias tecnológicas y psicosociales. Buenos Aires, Argentina: Novedades Educativas.

Mendoza, L., Gómez -Zermeño, M.G., Gómez-Zermeño, R.L. (2013). Desarrollo de habilidades cognitivas y tecnológicas con aprendizaje móvil. Revista de Investigación educativa de la Escuela de Graduados en Educación, 3(6), 30-39. Retrieved from: http://rieege.tecvirtual.mx/index.php/rieege/article/view/76

Merriam, S.B. (2009). Qualitative research. A guide to design and implementation. San Francisco, USA: Jossey Bass.

Rimari Arias, W. (1996) La innovación educativa: Un instrumento de desarrollo. Retrieved from: http://www.uaa.mx/direcciones/dgdp/defaa/descargas/innovacion_educativa octubre.pdf

Salat, R. (2013). La enseñanza de las matemáticas y la tecnología. Innovación educativa, 13(62), 61-74.

Valenzuela, J.R., \& Flores, M. (2012). Fundamentos de la Investigación Educativa (Volumen 2). Monterrey, México: Editorial Digital del Tecnológico de Monterrey.

\section{Published by OmniaScience (www.omniascience.com)}

Journal of Technology and Science Education, 2018 (www.jotse.org)

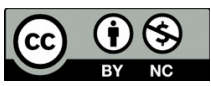

Article's contents are provided on an Attribution-Non Commercial 4.0 Creative commons International License.

Readers are allowed to copy, distribute and communicate article's contents, provided the author's and JOTSE

journal's names are included. It must not be used for commercial purposes. To see the complete licence contents, please visit https://creativecommons.org/licenses/by-nc/4.0/. 